\title{
The role of substrate materials in constructed wetland to remove $\mathrm{Cs}$
}

\author{
D. KOMÍNKOVÁ ${ }^{1 *}$, J. VACUlA $^{1}$
}

${ }^{1}$ Czech University of Life Sciences Prague, Faculty of Environmental Sciences, Kamýcká 129, Prague 6, 16500, Czech republic; (corespondence: kominkovad@,fzp.czu.cz) (vacula@,fzp.czu.cz)

\section{Introduction}

The paper presents the role of substrates materials in constructed wetlands for removal of $\mathrm{Cs}$ originating from radioactive liquid waste.

\section{Method}

The experimental approach was tested in physical models of $\mathrm{CW}$, forty $75 \mathrm{~L}$ containers were divided to 4 treatment groups with different composition of filtration beds. The common substrates were gravel and sand (default), than additional substrates as biochar, crushed bricks and technogenic soil (TS) were added. Three plants of Pragmites australis were planted in each container. The experiment was run with low and high hydraulic load. Stable Cs was provided as $0,5 \mathrm{mM}$ $\mathrm{CsCl}\left(0.0664 \mathrm{~g} / \mathrm{L} \mathrm{Cs}{ }^{+}\right)$. Cs concentrations in outflow were measured in 24 hours interval.

\section{Discussion of results}

The highest efficiency of Cs removal was observed for the default treatment, followed by technogenic soil, biochar and crushed bricks. High efficiency of default and TS filters agrees with Wang et al [1], who indicate their high efficiency for metals removal. The results indicate that in case of low hydraulic load, the CW have higher efficiency of Cs removal, while in case of high hydraulic load, the efficiency is lower and desorption of the pollutants may occur in the later phase, especially in case of biochar and crashed bricks.

[1] Wang et al (2020). Sci Total Environ. 701. A.N. 134736

\section{Acknowledgments}

This work was supported by the project of the Ministry of the Interior of the Czech Republic project number VI2VS/507. 